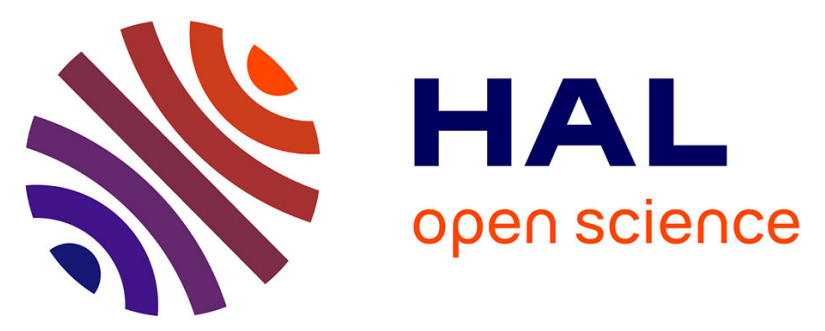

\title{
Comparison of main magnetic force computation methods for noise and vibration assessment in electrical machines
}

Raphaël Pile, Emile Devillers, Jean Le Besnerais

\section{- To cite this version:}

Raphaël Pile, Emile Devillers, Jean Le Besnerais. Comparison of main magnetic force computation methods for noise and vibration assessment in electrical machines. IEEE Transactions on Magnetics, 2018, 54 (7), pp.1-13. 10.1109/TMAG.2018.2828388 . hal-01960033

\section{HAL Id: hal-01960033 \\ https://hal.science/hal-01960033}

Submitted on 19 Dec 2018

HAL is a multi-disciplinary open access archive for the deposit and dissemination of scientific research documents, whether they are published or not. The documents may come from teaching and research institutions in France or abroad, or from public or private research centers.
L'archive ouverte pluridisciplinaire HAL, est destinée au dépôt et à la diffusion de documents scientifiques de niveau recherche, publiés ou non, émanant des établissements d'enseignement et de recherche français ou étrangers, des laboratoires publics ou privés. 


\title{
Comparison of main magnetic force computation methods for noise and vibration assessment in electrical machines
}

\author{
Raphaël PILE ${ }^{12}$, Emile DEVILLERS ${ }^{12}$, Jean LE BESNERAIS ${ }^{1}$ \\ ${ }^{1}$ EOMYS ENGINEERING, Lille-Hellemmes 59260, France (www.eomys.com) \\ ${ }^{2}$ Univ. Lille, Arts et Metiers ParisTech, Centrale Lille, HEI, EA 2697 - L2EP -Laboratoire d'Electrotechnique et \\ d'Electronique de Puissance, F-59000 Lille, France
}

\begin{abstract}
This paper presents a comparison of several methods to compute the magnetic forces experienced by the stator teeth of electrical machines. In particular, the comparison focuses on the Virtual Work Principle (VWP) based nodal forces and the Maxwell Tensor (MT) applied on different surfaces. The VWP is set as the reference. The magnetic field is computed either with Finite Element Analysis (FEA) or with the semi-analytical Subdomain Method (SDM). Firstly, the magnetic saturation in iron cores is neglected (linear B-H curve). Then, the saturation effect is discussed in a second part. Homogeneous media are considered and all simulations are performed in 2D. The link between slot's magnetic flux and tangential force harmonics is also highlighted.

The comparison is performed on the stator of a Surface-Mounted Permanent Magnet Synchronous Machine (SPMSM). While the different methods disagree on the local distribution of the magnetic forces at the stator surface, they give similar results concerning the integrated forces per tooth, referred as Lumped Forces. This conclusion is mitigated for saturated cases: the time harmonics are correctly computed with any of the presented Lumped Force methods but the amplitude of each harmonic is different between methods. Nonetheless, the use of semi-analytical Subdomain Method remains accurate with Maxwell Tensor in the air-gap even with saturation for design and diagnostic of electromagnetic noise in electrical machines. However, for more accurate studies based on local magnetic pressure, the Virtual Work Principle is strongly recommended.
\end{abstract}

Index Terms-Electromagnetic forces, Maxwell Tensor, Virtual Work Principle, Semi-analytical, Finite Element analysis, Electrical Machines, Electromagnetic noise.

\section{NOTATIONS}

$\begin{array}{ll}\text { FEA } & \text { Finite Element Analysis } \\ \text { SDM } & \text { Semi-analytical sub-domain method } \\ \text { VWP } & \text { Virtual Work Principle } \\ \text { MT } & \text { Maxwell Tensor } \\ \text { PMMF } & \text { Permeance Magneto-motive Force } \\ \text { RMS } & \text { Root mean square } \\ \mu & \text { Magnetic relative permeability } \\ \mathbf{B} & \text { Magnetic flux vector with components } B_{i} \\ \mathbf{H} & \text { Magnetic field vector with components } H_{i} \\ \mathbf{T} & \text { Maxwell Tensor with components } T_{i, j} \\ P_{m a g} & \text { Magnetic surface pressure } \\ f_{m a g} & \text { Magnetic bulk force } \\ A & \text { Acoustic pressure } \\ \mathbb{R} & \text { The space of real numbers } \\ \mathbb{N} & \text { The space of natural numbers } \\ \mathbf{B}^{i} & \text { The value which is taken by a vector field } \mathbf{B} \text { for the } i^{t h} \text { node } \\ u_{s} & \text { The projection of a vector } \mathbf{u} \text { onto the direction } \mathrm{s} \\ \partial_{x} u & \text { The partial derivative of u with respect to x } \\ \delta_{i, j} & \text { Kronecker delta symbol } \\ \int_{\Gamma} \text { The integration on a contour/surface } \Gamma \\ \nabla \cdot \mathbf{u} & \text { The divergence operator applied to a vector/tensor } \mathbf{u} \\ \nabla u & \text { The gradient operator applied to a scalar/vector } u \\ \mathbf{u . v} & \text { Euclidean scalar product between } \mathbf{u} \text { and } \mathbf{v} \\ |u| & \text { Euclidean norm of a vector } \mathbf{u} \\ A_{i, j} & \text { The element on the } i^{t h} \text { line and } j^{t h} \text { column of a matrix } \mathbf{A} \\ \mathbf{A} & \text { Inverse of a matrix } \mathbf{A}\end{array}$

\section{INTRODUCTION}

$\mathbf{I}$ $\mathrm{N}$ electrical machines, the study of noise and vibrations due to magnetic forces first requires the accurate calculation of Maxwell stress distribution which depends on the time and space distribution of the magnetic flux density. Indeed, a very small harmonic of magnetic force may induce large acoustic noise and vibrations due to a resonance with a structural mode of the stator. The magnetic flux can be determined everywhere in the machine with a Finite Element Analysis (FEA), only in the air-gap and windings with semi-analytical methods such as Sub-Domain Model (SDM) [1], or only in the middle of the air-gap using the permeance magneto-motive force (PMMF) [2].

In order to compute magnetic forces, a various range of methods can be found in the literature including: fictive magnetic currents and magnetic masses methods [3], energy methods [4], Maxwell Tensor (MT) methods [5], and Virtual Work Principle adapted to Finite Element (VWP) [6]. Then a compatible force computation method for the vibro-acoustic objectives must be chosen. As shown in Table I] the two flagship methods are the VWP and the MT but the preference for one method or another is not clearly justified in the documentation and articles linked to these software (see column Ref. of Table ID.

The discussion of local magnetic pressure is still on going [25] [26] [27] and should be the aim of further work. The VWP is built to account for magnetic force at each node from which the global quantities can be deduced, while the Maxwell tensor gives the momentum flux across any surface, closed or not [25]. Historically the Maxwell Tensor has been used by electrical machine designers to accurately compute global quantities such as electromagnetic torque, which is the moment of the global magnetic force applied on a cylinder surrounding the rotor on its axis of rotation. Under the common form the MT cannot be rigorously related to a local magnetic pressure but it is often used in vibro-acoustic studies to obtain the local force distribution in the air gap which applies on the stator structure [9] [12] [16] [21]. However such a method can have 
TABLE I

MAGNETO-MECHANICAL COUPLING AMONG SOFTWARE FOR VIBRO-ACOUSTIC

\begin{tabular}{|c|c|c|c|c|c|}
\hline EM Soft & Struct. Soft & Projection tool & Force calc. & Ref. & \\
\hline \multirow{5}{*}{ JMAG } & LMS & LMS & VWP & [7] & $\overline{8}]$ \\
\hline & NASTRAN & JMAG & MT & [9] & \\
\hline & ALTAIR & JMAG & MT & |9| & \\
\hline & ABAQUS & JMAG & MT & [9] & \\
\hline & JMAG & JMAG & VWP & [9] & \\
\hline \multirow{5}{*}{ FLUX } & ANSYS & ANSYS & $\begin{array}{l}\text { MT } \\
\text { VWP }\end{array}$ & [10] & \\
\hline & LMS & LMS & VWP & 111] & \\
\hline & ALTAIR & FLUX & MT & [12] & \\
\hline & NASTRAN & FLUX & MT & $|\overline{12}|$ & \\
\hline & MATLAB & MATLAB & VWP & $|\overline{12}|$ & {$[11]$} \\
\hline \multirow{2}{*}{ COMSOL } & COMSOL & COMSOL & MT & [13] & \\
\hline & MATLAB & MATLAB & $\begin{array}{l}\text { MT } \\
\text { VWP }\end{array}$ & |14] & $\mid 15$ \\
\hline \multirow{3}{*}{ ANSYS } & ANSYS & ANSYS & $\begin{array}{l}\text { MT } \\
\text { VWP }\end{array}$ & [16] & |17| \\
\hline & LMS & LMS & VWP & [18 & \\
\hline & NASTRAN & NASTRAN & MT & [16] & \\
\hline OPERA & OPERA & OPERA & $\begin{array}{l}\text { MT } \\
\text { VWP }\end{array}$ & |19] & \\
\hline FEMAG & FEMAG & FEMAG & MT & [20] & \\
\hline \multirow{2}{*}{$\begin{array}{l}\text { INFO } \\
\text { LYTICA }\end{array}$} & NASTRAN & FSI Mapper & MT & 21 & \\
\hline & ACTRAN & FSI Mapper & MT & 21 & \\
\hline GETDP & GETDP & GETDP & $\begin{array}{l}\text { MT } \\
\text { VWP }\end{array}$ & |22] & $\mid 23$ \\
\hline MANATEE & ALTAIR & MATLAB & $\begin{array}{l}\text { MT } \\
\text { VWP }\end{array}$ & |24| & \\
\hline
\end{tabular}

strong limitations depending on the geometry as shown by [18].

Consequently, a common method to compute the magnetomechanical excitations is to apply one integrated force per stator's tooth. It corresponds to the Lumped Force Mapping method proposed in [16]. A comparable integrated force per tooth can be obtained using the VWP or the MT. For the VWP, the integrated force per tooth is directly the resultant of the nodal forces computed inside the tooth. For the MT, it is obtained by integrating the magnetic pressure in the air gap over a path embracing/surrounding the tooth. Thus, this paper proposes a comparison of the most common methods under local and integrated forms with and without saturation effect. The simulations are performed on MANATEE [24] software, which is a privileged simulation framework for the electromagnetic and vibro-acoustics study of electrical machines and enables to compute the magnetic field with FEA and SDM.

The paper aims to compare local and lumped magnetic forces between the different forms of MT computed with SDM then confronted with magnetic forces obtained from FEA, while the VWP based on FEA is considered as the reference method (see section [II-B]. The possibility to use SDM with lumped force mapping under saturated conditions is also discussed. The originality of the present work resides in the comparison of the lumped force computation methods including harmonic content, for the main electromagnetic models used in the current vibro-acoustic studies. The paper also provides a clear explanation of the absence of bulk nodal forces with VWP when the magnetic permeability is constant.

\section{Machine topology}

The numerical values of the targeted Surface Permanent Magnet Synchronous Machine (SPMSM) machine with concentrated windings can be found in Table $\Pi$ based on the geometry presented in Fig. 1. The flux lines in load case (no saturation) is illustrated in Fig. 2. This specific geometry is used all along the paper first in linear case (Section IV-A) then with saturation (Section V). Similar geometry can be found in [28]. It is privileged because the polar geometry allows to accurately compute the magnetic field with semi-analytical methods. Moreover long and thin stator's teeth are concentrating considerable radial and tangential efforts on teeth's tips such that Lumped Force methods are justified for a structural simulation. A linear B-H curve and homogeneous media are considered for the whole machine. The geometry used in this paper has been successfully used with lumped force mapping by [29] with a MT applied in the air-gap showing the interest of such magneto-mechanical weak-coupling methods.

TABLE II

INPUT PARAMETERS OF THE SPMSM 12S-10P MACHINE SIMULATION

\begin{tabular}{|c|c|}
\hline Parameter & Value \& Unit \\
\hline \multicolumn{2}{|l|}{ Numerical } \\
\hline $\mathrm{N}$ (Rotation speed) & $400[\mathrm{rpm}]$ \\
\hline Total time steps & 160 \\
\hline Number of element $(\min / \max )$ & {$[9142 ; 10798]$} \\
\hline Number of nodes $(\min / \max )$ & {$[4888 ; 5564]$} \\
\hline FEA Formulation & Potential Vector \\
\hline \multicolumn{2}{|l|}{ Geometrical } \\
\hline$R_{r y}$ & $11.9[\mathrm{~mm}]$ \\
\hline$R_{r b o}$ & $23.9[\mathrm{~mm}]$ \\
\hline$R_{m}$ & $26.8[\mathrm{~mm}]$ \\
\hline$R_{s b o}$ & $27.9[\mathrm{~mm}]$ \\
\hline$R_{\text {slot }}$ & $46.8[\mathrm{~mm}]$ \\
\hline$R_{s y}$ & $50.0[\mathrm{~mm}]$ \\
\hline Slot angular width & 18 [deg] \\
\hline Tooth angular width & $12[\mathrm{deg}]$ \\
\hline Depth & $50[\mathrm{~mm}]$ \\
\hline \multicolumn{2}{|l|}{ Magnetic } \\
\hline$\mu_{0}($ Void permeability $)$ & $4 \pi 10^{-7}\left[\mathrm{H}_{\mathrm{H}} \mathrm{m}^{-1}\right]$ \\
\hline$\mu_{\text {stator }}$ (Iron relative permeability) & 2500 \\
\hline$\mu_{\text {magnet }}$ (Magnet relative permeability) & 1.05 \\
\hline$\mu_{\text {air }}$ (Air relative permeability) & 1 \\
\hline$B_{r m}$ (Magnet residual flux density) & $1.2[\mathrm{~T}]$ \\
\hline \multicolumn{2}{|l|}{ Windings } \\
\hline Synchronous frequency $f_{s}$ & $26.66[\mathrm{~Hz}]$ \\
\hline Phase current RMS & $10[\mathrm{~A}]$ \\
\hline $\begin{array}{l}\text { Number of } \\
\text { parallel circuits per phase }\end{array}$ & 1 \\
\hline Number of turns per coil & 34 \\
\hline
\end{tabular}

\section{Nodal forces with Virtual Work Principle}

\section{A. Formulas \& implementation}

Let $\mathbf{H}$ be the magnetic field, $\mathbf{B}$ the magnetic flux density, $H_{i}$ and $B_{i}$ their respective components in cartesian frame. The nodal force expression according to [6] is based on an equivalence between the magnetic co-energy variation and the force applied on a solid determined by the domain $\Omega$, such that the force amplitude in the direction $s \in\{\mathbf{x}, \mathbf{y}, \mathbf{z}\}$ is:

$$
F_{s}=\frac{\partial}{\partial s} \int_{\Omega} \int_{0}^{H} \mathbf{B} \cdot \mathrm{d} \mathbf{H} \mathrm{d} \Omega
$$




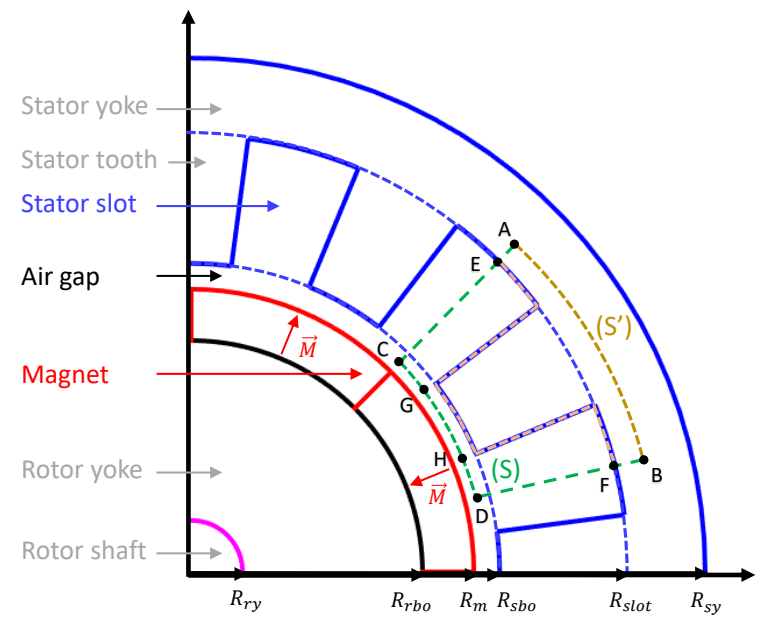

Fig. 1. Electrical motor geometry and parameters definition

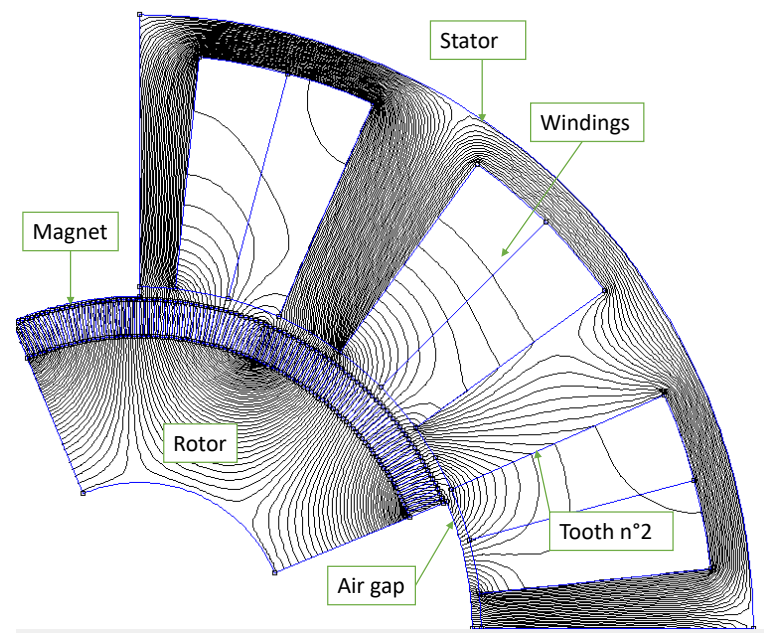

Fig. 2. Electrical motor flux map generated with FEMM [30] in loaded case

Applying this equation to a mesh element $e$ :

$F_{s}=\int_{e}\left(-\mathbf{B}^{T} \cdot \mathbb{J}^{-1} \cdot \frac{\partial \mathbb{J}}{\partial s} \cdot \mathbf{H}+\int_{0}^{H} \mathbf{B} \cdot \mathrm{d} \mathbf{H}\left|\mathbb{J}^{-1}\right| \frac{\partial|\mathbb{J}|}{\partial s}\right) \mathrm{dV}$

with $\mathbb{J}$ the Jacobian matrix of the element $e$. The derivatives of $\mathbb{J}$ can be determined knowing the type of element (triangular, rectangular, quadrilateral, tetrahedron ...). With a linear case, the integrand of $\mathbf{B}$ can be simplified as follow:

$$
\int_{0}^{H} \mathbf{B} \cdot \mathrm{d} \mathbf{H}=\int_{0}^{H} \mu \mathbf{H} \cdot \mathrm{d} \mathbf{H}=\frac{\mu}{2}|\mathbf{H}|^{2}
$$

with the amplitude $\mathbf{H}$ constant in each element. Thus the natural way to implement the VWP algorithm is to loop on each element, compute the previous formulas and add the element contribution to its nodes. Then a local force $F_{s}^{i}$ applying on a given node $i$ can be written as:

$F_{s}^{i}=\sum_{\forall e \mid i \in e} \int_{e}\left(-\mathbf{B}^{T} \cdot \mathbb{J}^{-1} \cdot \frac{\partial \mathbb{J}}{\partial s} \cdot \mathbf{H}+\frac{\mu}{2}|\mathbf{H}|^{2}\left|\mathbb{J}^{-1}\right| \frac{\partial|\mathbb{J}|}{\partial s}\right) \mathrm{d} \mathbf{V}$

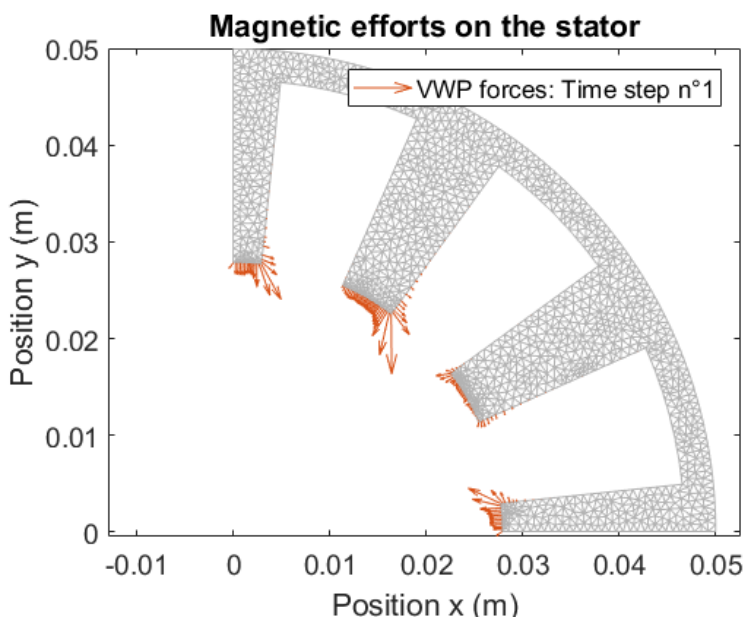

Fig. 3. Example of nodal magnetic force repartition using the VWP on the stator's mesh

\section{B. Discussion}

An overview of the magnetic force distribution according to Eq. (4) is illustrated in Fig. 3. A first observation is the concentration of nodal forces at the iron-air interface. This result is expected because of the linear homogeneous hypothesis media for the stator. In a linear electromagnetic media, the electromagnetic co-energy density $\psi$ can be expressed as:

$$
\psi(x, B(x))=(1 / \mu) \frac{|B|^{2}}{2}
$$

The virtual (or real) displacement function $p$ is defined:

$$
p: x \in \mathbb{R}^{2} \rightarrow p(x) \in \mathbb{R}^{2}
$$

Then the variation of energy density linked to $p$ in case of weak-coupling is calculated:

$$
\begin{array}{r}
\psi(p(x), B(p(x)))-\psi(x, B(x)) \approx \\
\psi(p(x), B(x))-\psi(x, B(x))= \\
{\left[(1 / \mu(p(x))-1 / \mu(x)] \frac{|B(x)|^{2}}{2}\right)}
\end{array}
$$

In the case of linear elasticity (small displacement) $\exists h \in \mathbb{R}^{2}$, $p(x)=x+h$ with $h \rightarrow 0$ such that :

$$
\begin{array}{r}
\partial_{p} \psi(B)=\lim _{h \rightarrow 0} \frac{\psi(x+h, B(x))-\psi(x, B(x))}{h} \\
=\lim _{h \rightarrow 0} \frac{1 / \mu(x+h)-1 / \mu(x)}{h} \frac{|B(x)|^{2}}{2} \\
=\nabla(1 / \mu) \frac{|B(x)|^{2}}{2}
\end{array}
$$

The virtual work principle theorem (not the VWP method applied to FEA, see [31] for explanations) allows to identify the magnetic bulk force $f_{m a g}$ as the variation of co-energy:

$$
f_{\text {mag }}=\partial_{p} \psi(B)=\nabla(1 / \mu) \frac{|B(x)|^{2}}{2}
$$

Therefore, if the B-H curve is linear and $\mu$ constant in the stator, then we have $f_{\text {mag }}=0$. Then it is logical to observe the absence of bulk forces with the VWP since it is based on a similar derivation of the co-energy. The previous equation has 


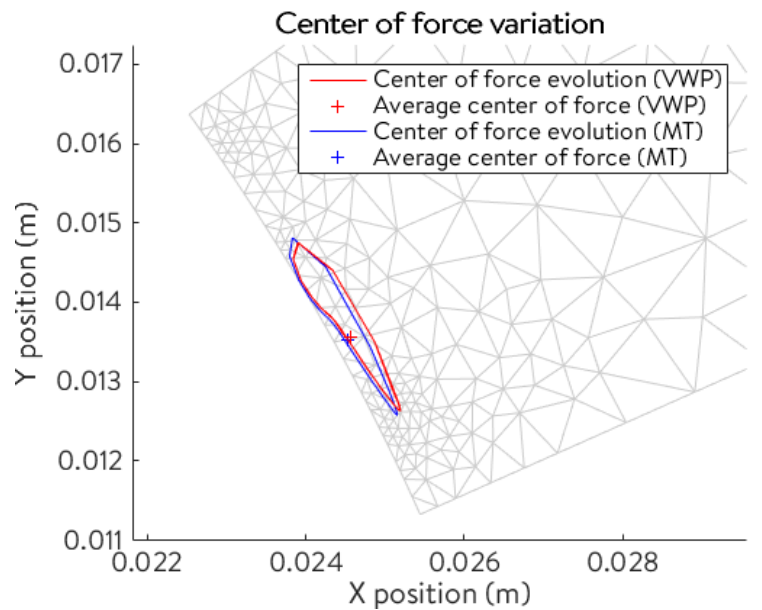

Fig. 4. Barycenter of forces trajectory during one revolution according to VWP nodal forces

been already stated by [32] and more recently by [33] in an attempt to generalize the Maxwell Tensor on interfaces such as iron-air. This results means the sensitivity of the geometry to saturation can highly impact the level of bulk forces per tooth and therefore the barycenter of the forces.

In Fig. 3 another observation is the concentration of the forces on the tip of each tooth. In order to investigate the accuracy of lumped force applied at the tooth tip, Fig. 4 presents the displacement range of the barycenter of force $\left(x_{G}, y_{G}\right)$ for one tooth over one revolution. For each tooth, the barycenter is computed by summing the contribution of all nodes $i$ belonging to the tooth:

$$
\left(\begin{array}{l}
x_{G} \\
y_{G}
\end{array}\right)=\frac{\sum_{i}\left(\begin{array}{l}
F^{i} x_{i} \\
F^{i} y_{i}
\end{array}\right)}{\sum_{i} F^{i}}
$$

with $F^{i}=\sqrt{\left(F_{x}^{i}\right)^{2}+\left(F_{y}^{i}\right)^{2}}$ the $L^{2}$ norm of the force applied on the $i^{\text {th }}$ node and $\left(x_{i}, y_{i}\right)$ its Cartesian coordinates. On average, the center of force is close to the center of the tooth tip and under $2 \%$ of the total tooth height. The asymmetrical path and the difference between the average center and the tooth's tip center are explained by the asymmetrical average tangential forces between both edges, which produce the electromagnetic torque. The linear hypothesis also means that both magnetic co-energy and magnetic energy are equivalent. However, this energetic symmetry is lost with non-linear media (by example for permanent magnets) resulting in different forces distribution between co-energy and energy based formulation [34]. The possibility of having an external rotor motivates work such as [35] [36] [27] about the virtual work principle for nonlinear media and the application to vibroacoustic.

\section{MAXWELl TENSOR MAGNETIC PRESSURE}

\section{A. Formulas \& implementation}

The Maxwell stress tensor $\mathbf{T}$ is commonly defined with the following component:

$$
\mathbf{T}_{i, j}=B_{i} H_{j}-\frac{\mu}{2} \delta_{i, j} \sum_{k=1}^{n}\left|H_{k}\right|^{2}
$$

Defining a surface $S$ around a volume $V$, such that the divergence theorem can be applied, with $\mathbf{n}$ the outer normal to $S$. Then the global force $\mathbf{F}$ applying on the volume $V$ is:

$$
\mathbf{F}=\iiint_{V} \nabla \cdot \mathbf{T d V}=\oint_{S}\left((\mathbf{B} \cdot \mathbf{n}) \mathbf{H}-\frac{\mu}{2}|\mathbf{H}|^{2} \mathbf{n}\right) \mathrm{d} \mathbf{S}
$$

Applied to the ferromagnetic tooth surrounded by a dotted circular path as in Fig. 11. the force can be written under the form:

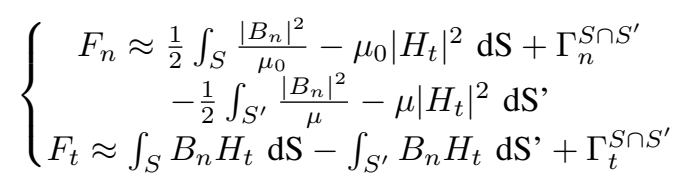

with $\mu$ the magnetic permeability, $\mu_{0}$ the void permeability, $X_{n}$ and $X_{t}$ the components of a vector field respectively projected on $\mathbf{n}$ and $\mathbf{t}$ (respectively normal and tangential local vectors attached to a surface) and $\Gamma^{S \cap S^{\prime}}$ a gap term corresponding to the integration over the interface between the stator and the air. This form assumes the previous application of the divergence theorem is still valid when crossing a discontinuity of permeability which is the interface stator-air. It can be achieved using the mathematical distribution theory and an integration in the distribution sense.

However the common form used to compute forces applying on one tooth is:

$$
\left\{\begin{array}{l}
F_{n} \approx \frac{1}{2} \int_{S} \frac{\left|B_{n}\right|^{2}}{\mu_{0}}-\mu_{0}\left|H_{t}\right|^{2} \mathrm{dS}-\frac{1}{2} \int_{S^{\prime}} \frac{\left|B_{n}\right|^{2}}{\mu}-\mu\left|H_{t}\right|^{2} \mathrm{dS} \\
F_{t} \approx \int_{S} B_{n} H_{t} d S-\int_{S^{\prime}} B_{n} H_{t} \mathrm{~d} S^{\prime}
\end{array}\right.
$$

assuming $\Gamma^{S \cap S^{\prime}}$ is null. Indeed, the numerical effect is negligible [37] when the integration surface is going through the interface at points such as $E$ and $F$ in Fig. 1 where the magnetic flux in the air is low. Adding the hypothesis $\mu \gg \mu_{0}$, the force expression is commonly reduced to:

$$
\left\{\begin{array}{l}
F_{n} \approx \frac{1}{2} \int_{S} \frac{1}{\mu_{0}}\left|B_{n}\right|^{2}-\mu_{0}\left|H_{t}\right|^{2} \mathrm{dS} \\
F_{t} \approx \int_{S} B_{n} H_{t} \mathrm{dS}
\end{array}\right.
$$

In the vibro-acoustic context, simplifying assumptions are often added by neglecting the $H_{t}$ terms which leads to:

$$
\left\{\begin{array}{l}
F_{n} \approx \frac{1}{2} \int_{S} \frac{1}{\mu_{0}}\left|B_{n}\right|^{2} \mathrm{dS} \\
F_{t} \approx 0
\end{array}\right.
$$

These simplifications are coherent with analytical methods like PMMF which only compute radial magnetic field. It may be justified by the small effect of tangential lumped forces on the structural modes excitation [38]. To the authors knowledge, these assumptions have not been rigorously proved when considering local magnetic pressure.

\section{B. Discussion}

At this point, the integrand in Eq. 13 could be identified as a local magnetic pressure, as represented in Fig. 5 Moreover, the previous VWP results, which show that the forces are indeed concentrated at the iron-air interface, corroborate the existence of such local magnetic pressure. But as mentioned previously, it implies to arbitrary neglect some parts of the integration surface. A rigorous application 


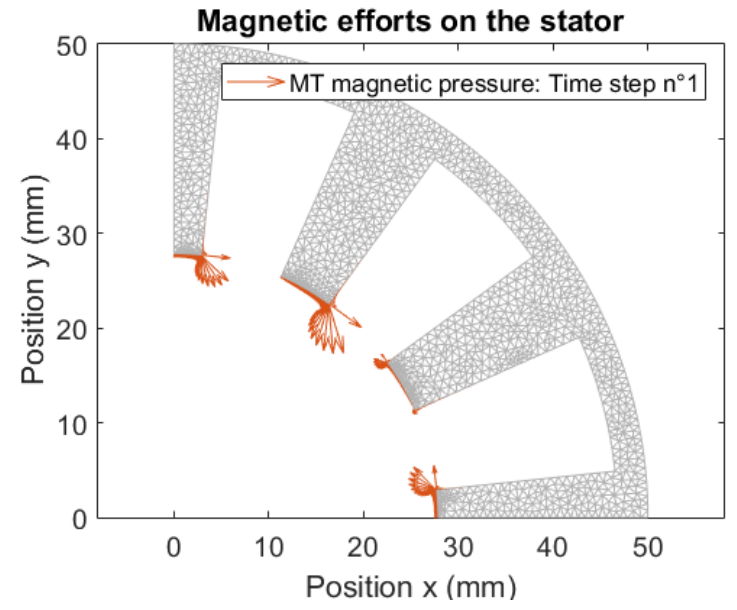

Fig. 5. Example of magnetic pressure repartition on the stator applying the MT along the stator inner surface

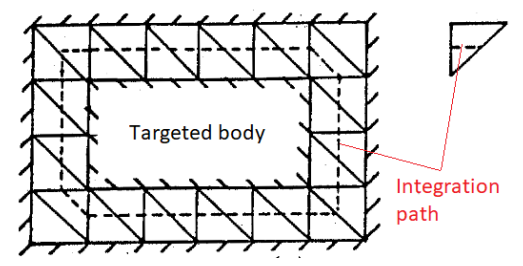

Fig. 6. Optimal contour for Maxwell-Tensor integration according to [41

of the MT is discussed in [27]. Even under the integrated form, there are many discussions about the choice of the integration surface, and its high influence on the vibro-acoustic results is a well-known problem [39] [40]. According to [41], the best choice with triangular finite elements is to cross the middle of the closest edges around the moving part, as illustrated in Fig. 6 with a closed path around a rectangular targeted body. It agrees with [42] saying the integration surface should stay close to the targeted body. However, the construction of such a contour requires to find the correct edges and their neighborhoods. This operation increases the computation/implementation complexity especially with sharp or non-standard geometry and the precision gain might not be huge. Moreover, the FEA formulation rely on a magnetic potential which can be scalar or vector, and leads to the the continuity of respectively $H_{t}$ or $B_{n}$, but not both at the same time. The error made on the numerically discontinuous physical quantity when going through an interface can impact the Maxwell Tensor [43], contrary to the VWP which can be adapted in order to be defined in function of the potential vector [44]. These different reasons explain why so many FEA software rely on the extrapolation of the middle air gap force to either the lumped tooth model or local magnetic pressure at tooth tip.

Regarding the semi-analytical methods, the magnetic field is not discretized such that the MT can be easily computed along any path. However, close to geometrical singularities (such as the corner of the teeth) some unphysical Gibbs phenomenon can appear [45]. To avoid this particular issue the MT is

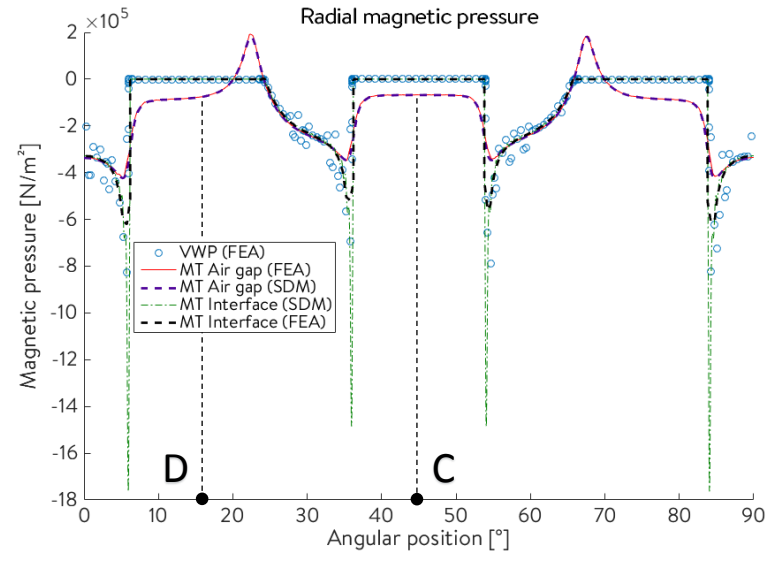

Fig. 7. Computing magnetic pressure in function of the angular position according to the VWP, the MT along the interface and the MT in the air-gap.

commonly computed at a certain distance of any interface (for example in the middle of the air-gap).

Concerning analytical methods (PMMF), only the normal magnetic field component in the air-gap is available, such that the MT computed in this context is equivalent to Eq. (14).

Although the local force density may be wrongly estimated, the MT ensures that integrated forces and torque are correctly conserved. It is coherent with the historical use of Maxwell Tensor by electrical machine designers to accurately compute torque. Moreover, [46] shows that approximation can be good enough to successfully predict the experimental thrust force using a MT local magnetic pressure with semi-analytical methods.

\section{Methods Comparison: Linear CASE}

\section{A. Local magnetic pressure}

Fig. 7 compares local radial magnetic pressure computation according to different methods applied to the electrical machine in Fig. 2 Three different methods are compared: the VWP computation based on FEA with FEMM [30], a "MT Interface" applied along the interface stator-air based on both SDM and FEA simulations, and a "MT Air gap" applied at constant radius in the middle of the air-gap based on FEA. Details about the application of these methods are provided in Table III The three different MT methods rely on Eq. (13) without the integrand. As observed in both Fig. 7 and 8 methods do not match each other on teeth tip, especially close to the corner of the teeth. As expected, the magnetic pressure distribution highly depends on the choice of the distance between the integration path and the interface [43]. Since the objective is the vibro-acoustic analysis, a logarithmic scale is more adapted because the acoustic level $A$ related to the magnetic force amplitude $F$ is generally expressed in dB:

$$
A \propto 20 \log \left(\frac{F}{F_{\text {ref }}}\right)
$$

with $F_{r e f}$ a reference force. In this paper case $F_{r e f}=1$ $[\mathrm{N}]$ is used. Thus the magnetic forces are represented on a logarithmic scale in Fig. 8 for radial component and in Fig. 9 for the tangential component. The abscissa of these figures 


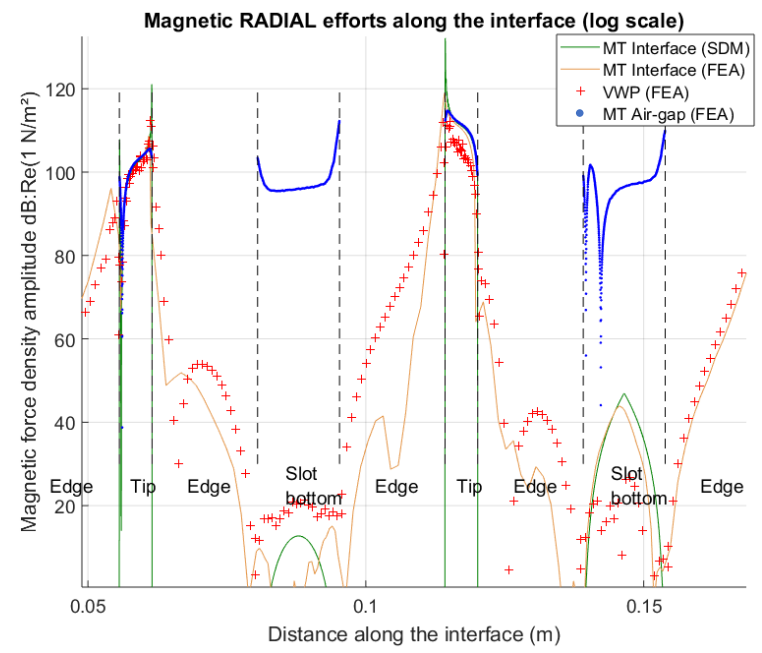

Fig. 8. Computing radial magnetic pressure along the interface according to the VWP, the MT along the interface and the MT in the air-gap.

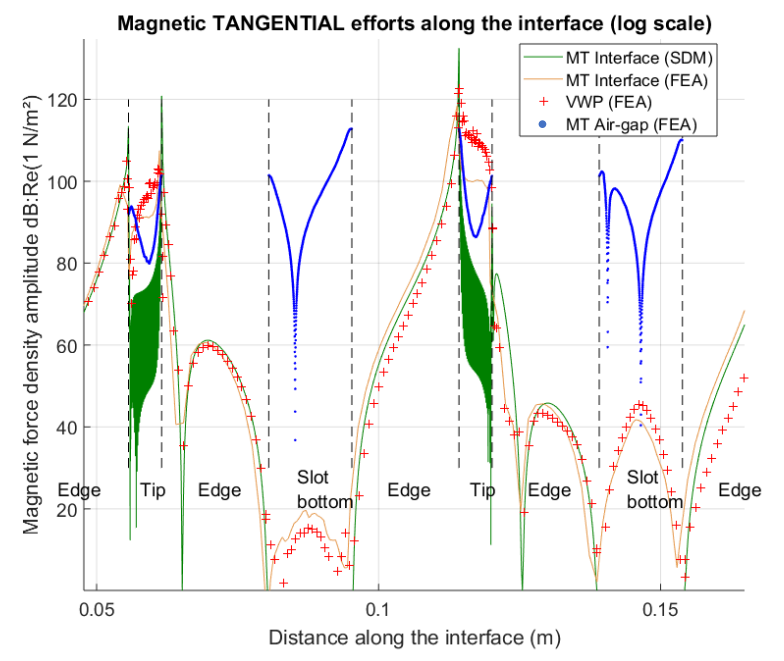

Fig. 9. Computing tangential magnetic pressure along the interface according to the VWP, the MT along the interface and the MT in the air-gap.

represents the curvilinear interface defined as the beige dotted path between $\mathrm{F}$ and $\mathrm{E}$ on Fig. 1 .

The dependence of the MT with the distance to the interface is even more clear in front of the slots. Initially, the MT is based on a volume, which is reduced to surface through a numerical approximation. This approximation is fulfilled in a linear case with a very high permeability for the stator. Then the tangential magnetic component $\mathbf{H}_{t}=0$ and the normal flux $\mathbf{B}_{n}$ is nearly constant close to the interface, such that the MT tends to the following magnetic pressure $P_{\text {mag }}$ approximation:

$$
P_{\text {mag }} \approx \frac{1}{2 \mu_{0}}\left|B_{n}\right|^{2}
$$

which is accurate for linear, planar surface with $\mu_{\text {stator }} \gg 1$. However, the geometric singularities (corners) do not satisfy these assumptions. An estimation of the mesh sensitivity on the lumped forces is given below in Fig. 11. The discretization effect has already been the subject of several papers and is not

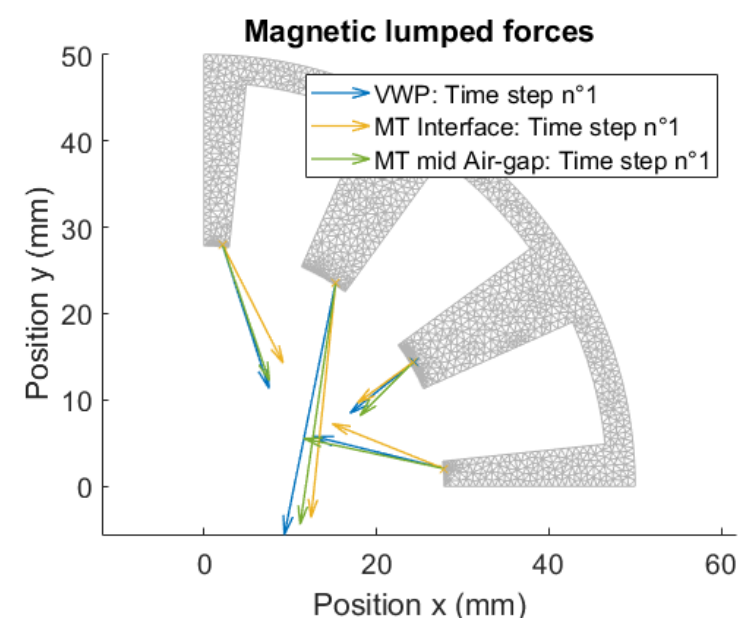

Fig. 10. Computing integrated tooth forces: Example of lumped forces amplitude and direction per teeth according to different methods.

further studied in this paper. A mesh sensitivity of the MT is discussed in [47], a comparison of the mesh effect on both MT and VWP is proposed in [48] for torque estimation, further investigations about the accuracy of the MT depending on the integral surface are available in [49], and error estimation for the VWP is proposed in [50]. Besides, the use of semianalytical methods overcomes meshing issues. Although the local magnetic forces may be wrongly estimated, there is a consensus about the reliability of the MT for torque prediction. As shown in the following sections the MT ensures Lumped Forces harmonics are correctly conserved as well.

\section{B. Lumped force mapping}

In this section, the previous magnetic pressures are integrated and compared for a vibro-acoustic purpose. First an example of the results with these Lumped Forces is presented in Fig. 10. In order to take the VWP as the reference, it must be checked that the discretization error is small behind the differences between the force methods. An overview of the VWP sensitivity to the fineness of the mesh is illustrated in Fig 11. seven different cases are computed where the overall number of elements is multiplied by a coefficient between 0.25 and 2 , where 1 corresponds to the automatic mesh size proposed by FEMM. The finest case (ratio equal to 2) is taken as the reference (approximately 21000 elements) for curves "VWP mesh sensitivity" and "MT mesh sensitivity" in order estimate the discretization errors. Other curves estimates the differences between two methods for different sizes of mesh. The discretization error is relatively small in all cases, and become negligible if the discretization is sufficiently fine. Then it also justifies to set VWP as the reference. To better understand the notion of magnetic momentum represented by the MT, additional versions of the MT lumped forces are computed in the following. The set of methods is summarized in the Table III

The first global value which can be numerically compared is the magnetic torque applying on the stator in Table IV] There are already two methods which seem to underestimate the 


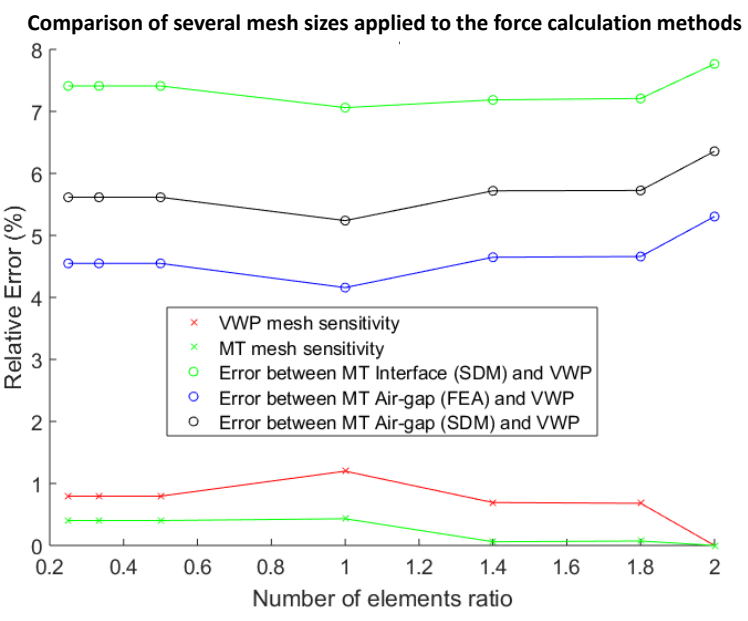

Fig. 11. The relative error between the VWP and MT and the discretization error

TABLE III

SET OF FORCE METHODS USED FOR THE LUMPED FORCE COMPARISON

\begin{tabular}{|c|c|c|}
\hline Name & Force method & Magnetic field method \\
\hline MT Air-gap & $\begin{array}{l}\text { Maxwell Tensor computed } \\
\text { according to Eq. } 13 \text {. } \\
\text { along the green curve } \\
\text { between point D \& C } \\
\text { on Fig. 1. }\end{array}$ & $\begin{array}{l}\text { SDM with MANATEE } \\
\text { or } \\
\text { FEA with FEMM }\end{array}$ \\
\hline MT Interface & $\begin{array}{l}\text { Maxwel Tensor computed } \\
\text { according to Eq. } 13 \text {. } \\
\text { along the beige curve } \\
\text { between point F \& E } \\
\text { on Fig. 1. }\end{array}$ & $\begin{array}{l}\text { SDM with MANATEE } \\
\text { or } \\
\text { FEA with FEMM }\end{array}$ \\
\hline VWP & $\begin{array}{l}\text { Virtual work principle } \\
\text { applied to Finite Element } \\
\text { according to Eq. }\end{array}$ & FEA with FEMM \\
\hline MT-radial & $\begin{array}{l}\text { Maxwell Tensor computed } \\
\text { according to Eq. 14. } \\
\text { along the green curve } \\
\text { between point D \& C } \\
\text { on Fig. 1 }\end{array}$ & SDM with MANATEE \\
\hline MT Tooth Tip & $\begin{array}{l}\text { Maxwell Tensor computed } \\
\text { according to Eq. 13. } \\
\text { along the green curve } \\
\text { between point } \mathrm{H} \& \mathrm{G} \\
\text { on Fig. 1. }\end{array}$ & SDM with MANATEE \\
\hline
\end{tabular}

TABLE IV

GLOBAL TORQUE ON THE MACHINE OF TABLE[I] WITH A LINEAR B-H CURVE SIMULATION

\begin{tabular}{|l|c|}
\hline Average torque & Value [N.m] \\
\hline MT Radial (SDM) & 0 \\
\hline MT Tooth Tip (SDM) & -5.1 \\
\hline MT Air-gap (SDM) & -8.1 \\
\hline MT Interface (FEA) & -8.2 \\
\hline MT Air-gap (FEA) & -8.0 \\
\hline VWP (FEA) & -7.4 \\
\hline MT Interface (SDM) & -7.9 \\
\hline
\end{tabular}

torque: MT Radial and MT Tooth Tip. Nonetheless, the radial forces are the most important source of electrical vibration, such that the contribution of these methods to the radial direction must be checked before any conclusion. Then for each tooth, the integrated forces computed according to the different methods are represented in Fig. 12 for the radial
TABLE V

RADIAL LUMPED FORCE RELATIVE DEVIATION

\begin{tabular}{|l|c|c|c|c|}
\cline { 2 - 5 } \multicolumn{1}{c|}{} & \multicolumn{4}{c|}{ Harmonic error [\%] } \\
\hline LF Method & $f_{0}$ & $f_{1}$ & $f_{2}$ & $f_{3}$ \\
\hline MT Air-gap (FEA) & -5 & -4 & +17 & -5 \\
\hline VWP (FEA) [Reference] & 0 & 0 & 0 & 0 \\
\hline MT Radial (SDM) & +8 & -9 & -20 & -31 \\
\hline MT Tooth Tip (SDM) & -33 & -24 & -37 & -64 \\
\hline MT Air-gap (SDM) & -6 & -6 & +15 & -7 \\
\hline MT Interface (SDM) & -10 & -7 & -28 & -28 \\
\hline
\end{tabular}

TABLE VI

TANGENTIAL LuMPED FORCE RELATIVE DEVIATION

\begin{tabular}{|l|c|c|c|c|}
\cline { 2 - 5 } \multicolumn{1}{c|}{} & \multicolumn{4}{c|}{ Harmonic error [\%] } \\
\hline LF Method & $f_{0}$ & $f_{1}$ & $f_{2}$ & $f_{3}$ \\
\hline MT Air-gap (FEA) & +10 & +15 & +33 & +5 \\
\hline VWP (FEA) [Reference] & 0 & 0 & 0 & 0 \\
\hline MT Radial (SDM) & $\infty$ & $\infty$ & $\infty$ & $\infty$ \\
\hline MT Tooth Tip (SDM) & -73 & -60 & +1 & -77 \\
\hline MT Air-gap (SDM) & +8 & +13 & +30 & +3 \\
\hline MT Interface (SDM) & -22 & -28 & -32 & -17 \\
\hline
\end{tabular}

TABLE VII

ACOUSTIC AMPLITUDE RELATIVE DEVIATION WITH RESPECT TO LUMPED FORCE EUCLIDEAN NORM

\begin{tabular}{|l|c|c|c|}
\cline { 2 - 4 } \multicolumn{1}{c|}{} & \multicolumn{3}{c|}{ Harmonic error [dB] } \\
\hline LF Method & $f_{1}$ & $f_{2}$ & $f_{3}$ \\
\hline MT Air-gap (FEA) & -0.06 & -3.8 & +0.25 \\
\hline MT Air-gap (SDM) & +1 & +2.5 & +4 \\
\hline Reference amplitude (VWP) & $143 \mathrm{~dB}$ & $110 \mathrm{~dB}$ & $98 \mathrm{~dB}$ \\
\hline
\end{tabular}

component, on Fig. 13 for the tangential component. The resulting frequencies $f_{n}$ of the force harmonics are even multiple of the fundamental electrical frequency $f_{s}$ and the number of poles $p$ :

$$
f_{n}=2 n f_{s}=(2 n) p \frac{N}{60} \approx(53.33) n\left[H_{z}\right], \forall n \in \mathbb{N}
$$

This result is observed for all three methods on Fig. 12 and Fig. 13 after performing a Fast Fourier Transform (FFT) on the discrete temporal signals. All methods provide the same frequency content, only the magnitude of the harmonics differ. Table $\mathrm{V}$ and Table VI summarize the deviation from the VWP (set as the reference). These values definitely show that the MT Air-gap (either SDM or FEA) should be preferred over other form of Maxwell Tensor. It can be pointed out that errors are still important (more than 5\%) with respect to VWP even when using the MT Air-gap but converting these differences into the acoustic amplitude log scale, the errors are relatively minored as shown in the Table $\mathrm{VII}$; on the predominant harmonic $f_{1}$, it can be expected to do a relative error less than $1 \mathrm{~dB}$, which is generally inferior to measurement precision. Moreover, effect of numerical noise can be observed in Fig. 14 for VWP (and to a lesser extent for the MT Interface (FEA)) through small non-physical harmonics. This noise is due to mesh discretization. Besides only three out of five methods really account for the tangential direction contribution: VWP, MT Air-gap and MT Interface. Indeed only the MT methods which take into account the slot magnetic flux can capture correctly the tangential Lumped Force: MT Tooth Tip underestimates the radial force significantly and neglecting the tangential 

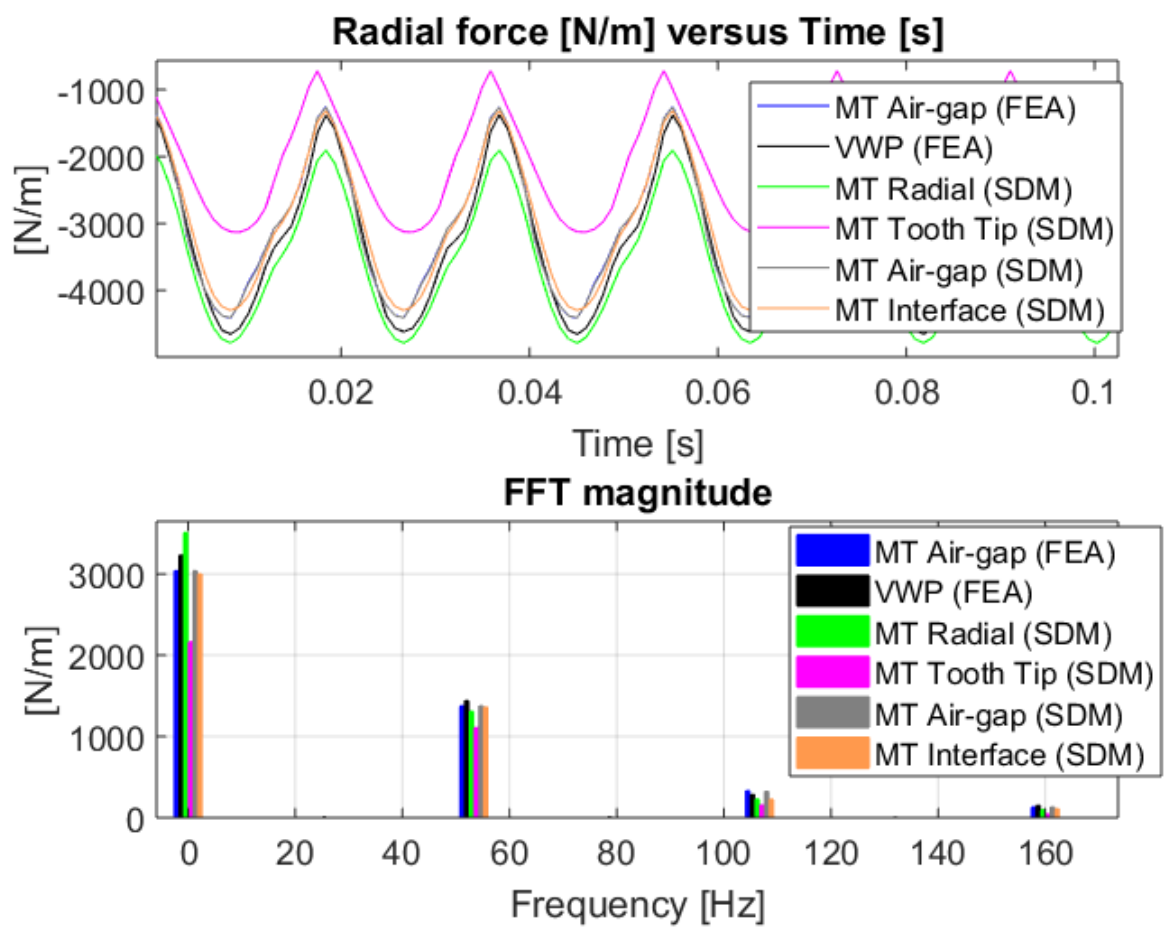

Fig. 12. Radial lumped force during one revolution and its FFT according to different methods with a linear B-H curve

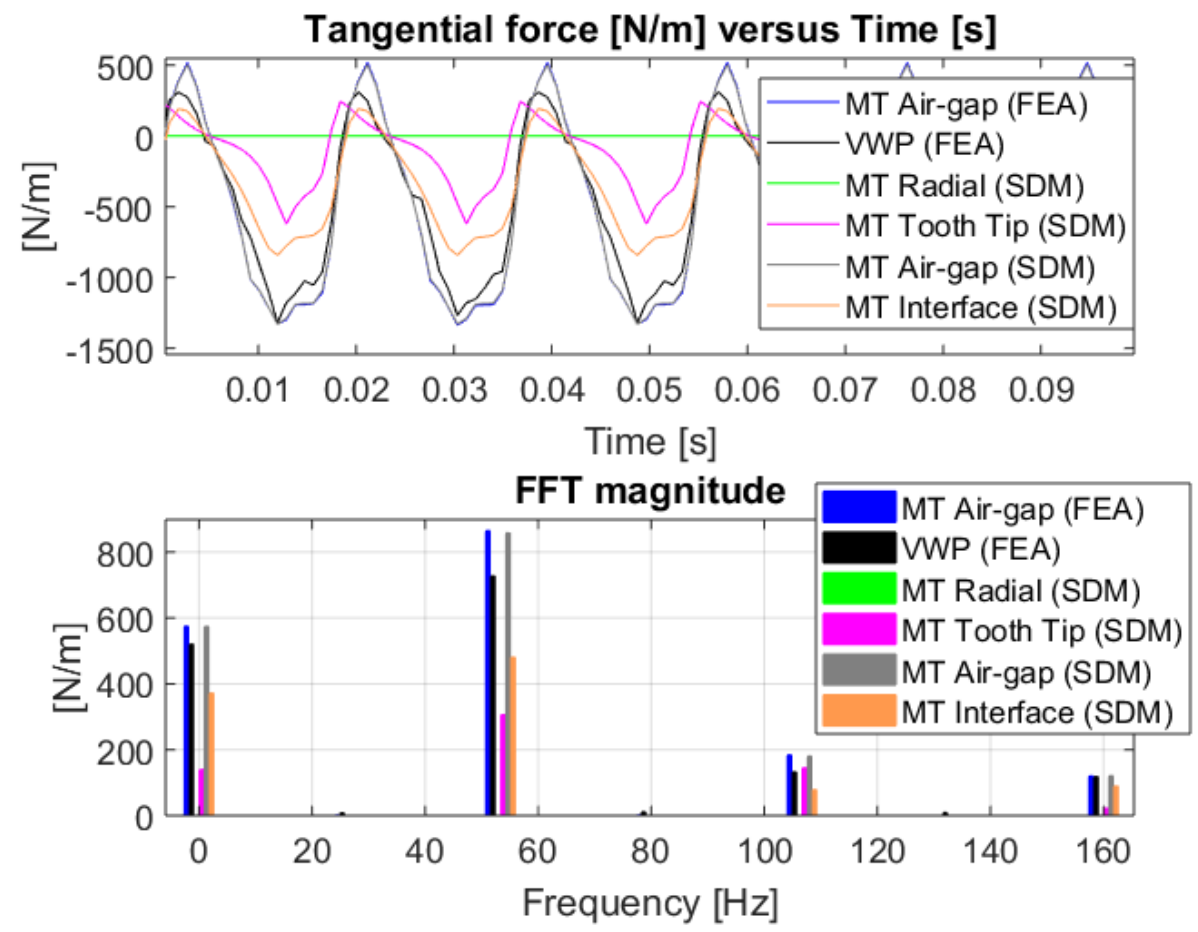

Fig. 13. Tangential lumped force during one revolution and its FFT according to different methods with a linear B-H curve

magnetic flux (with the MT-radial) leads to overestimate the radial lumped force. Knowing that tangential harmonics can excite radial modes as shown in [38], it can be conclude that MT-radial and MT Tooth Tip are inadequate for vibro-acoustic context even though it can be found in some articles such as [51].
Since the harmonics and amplitudes of the forces are very close, the following methods are nearly equivalent from a vibro-acoustic point of view: VWP, MT Interface, MT Air-gap and MT FEMM. Then the lumped force mapping can be used for vibro-acoustic prediction with similar tooth geometry. For example, [29] presented a successful prediction of the noise 


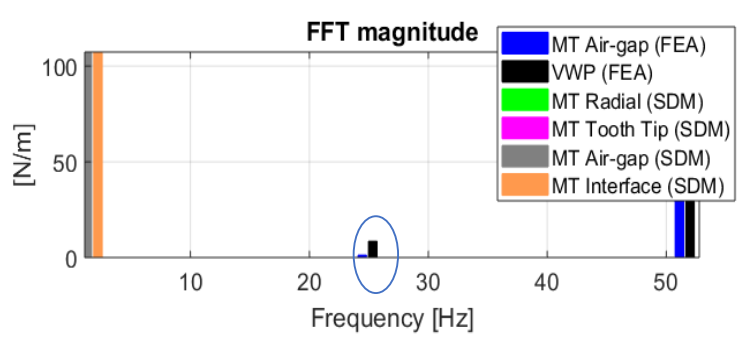

Fig. 14. Integrated tooth forces: Zoom on the FEA noise on the lumped tangential forces

TABLE VIII

MODIFIED PARAMETERS OF THE MACHINE WITH SATURATION

\begin{tabular}{|l|c|}
\hline New Parameter & Value \& Unit \\
\hline Magnets $B_{r m}$ & $1.4[\mathrm{~T}]$ \\
\hline Phase current RMS & $25[\mathrm{~A}]$ \\
\hline
\end{tabular}

with lumped force mapping using the MT Air-gap. The case of Table $\Pi$ has a good agreement between linear and non-linear simulations. In order to start a study about the saturation effect, the following section proposes to keep the same geometry with higher injection currents and higher remanent magnetization.

\section{SATURATION EFFECT}

In this section, the simulation is now performed with the same geometry but the injected current and the remanent magnetization of the rotor's magnet are both increased. The modified magnetic and windings parameters can be found in Table VIII The FEMM simulation is performed with a nonlinear B-H curve presented in Fig. 15, such that the saturation can be computed. The authors refer to [52] for the FEA modeling of saturation and [53] for its influence on permanent magnet machine performances.

Saturation has as consequence a local drop of magnetic permeability. It corresponds to the flattened part of the curve in Fig. 15 for high amplitude of $\mathbf{H}$. In particular for electrical machines, the saturation appears on tooth tip where the concentration of magnetic flux is the most intense. It creates a gradient of permeability across the media such that a magnetic bulk force (orthogonal to iso-permeability lines) is obtained according to Eq. (7). The VWP is adapted to compute nodal forces with saturation by numerically compute the co-energy integrand of Eq. (3), which corresponds to the area under the curve in Fig. 15. It allows to compute the bulk forces inside the ferromagnetic media. Thus magnetic forces are not completely concentrated at the interface unlike the linear case. Though the barycenter of forces in Fig. 17 is pushed back into the stator compared to Fig. 4 the highest point is approximately at $22 \%$ of the total tooth height, such that the application of the force at the tip of the tooth starts to be questionable. On the other hand, the MT cannot account for the local bulk behavior. The global force is distributed on the surface of the tooth such that the MT Interface approximation of the barycenter position in Fig. 17 is distort.

The SDM simulation is not accounting for the saturation effect on the magnetic flux, resulting in differences presented

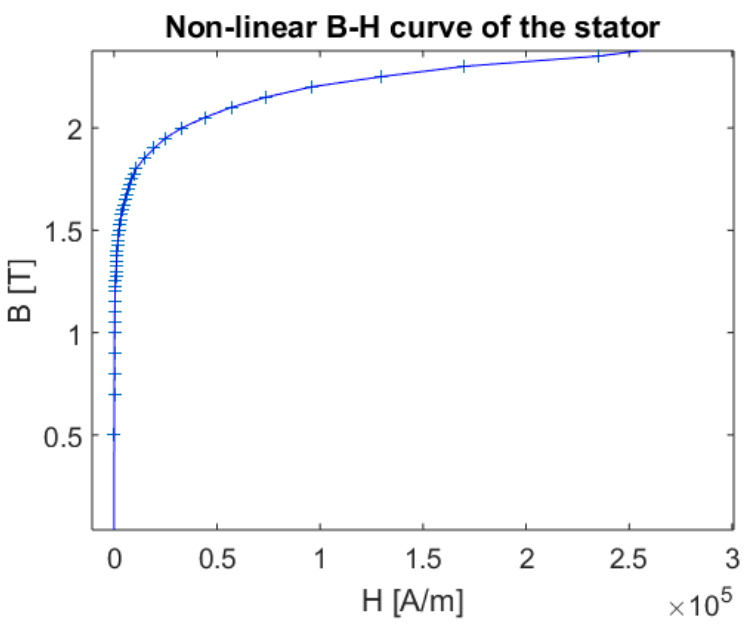

Fig. 15. Non-linear B-H curve used for the stator in FEMM

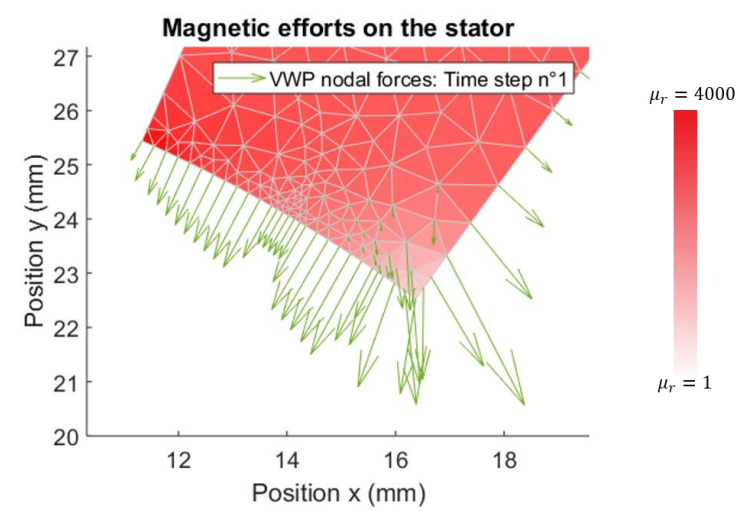

Fig. 16. Apparition of bulk force in saturated conditions according to VWP

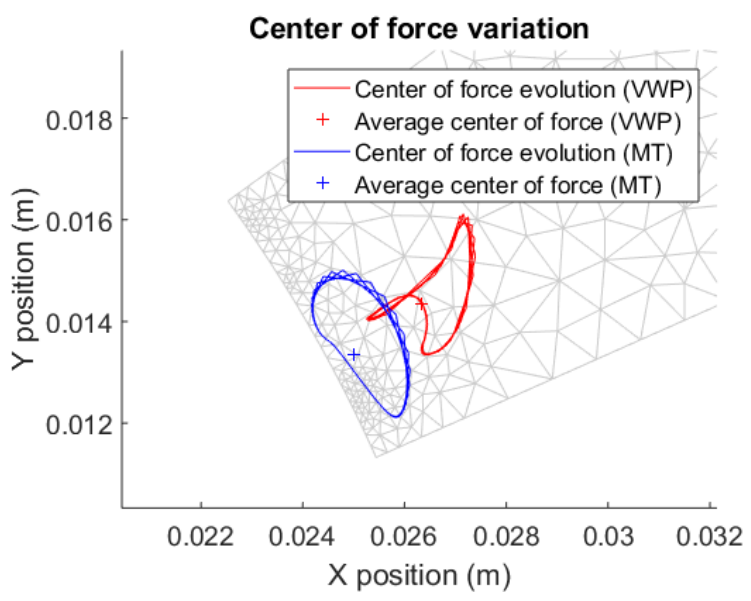

Fig. 17. Barycenter of forces trajectory during one revolution (simulation with saturation)

in Fig. 18, the temporal harmonic content on the flux is the same but the amplitude differs on the fundamental and the first harmonic. Indeed, the saturation is flattening the spatial distribution of magnetic flux such that the first harmonics are lower than SDM results. As previously done for the linear case, the first global parameter to study is the magnetic torque. 

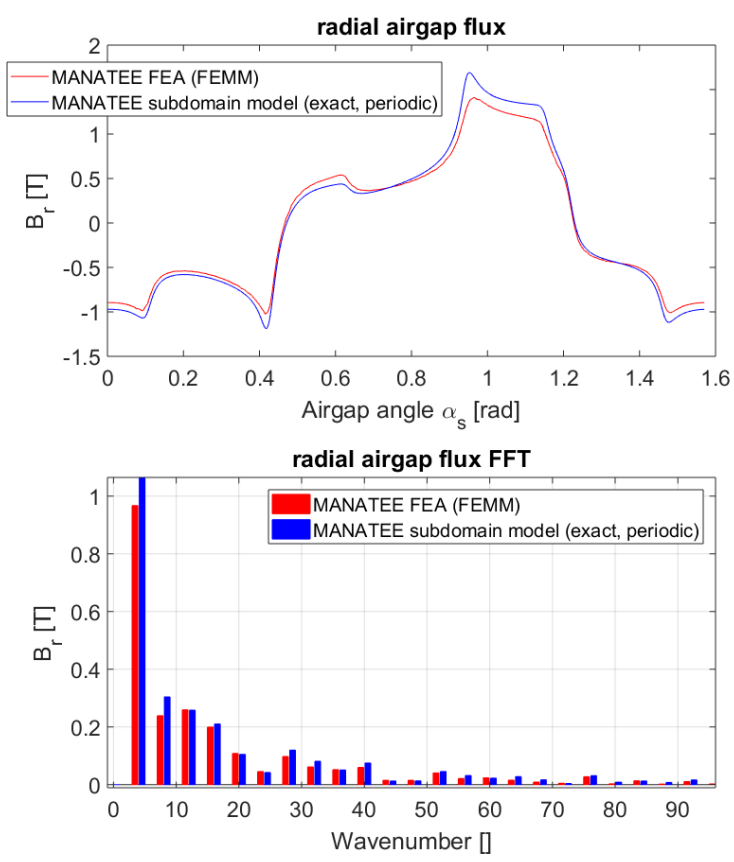

Fig. 18. Comparison between FEA with saturation and SDM

TABLE IX

GLOBAL TORQUE ON THE MACHINE WITH SATURATION

\begin{tabular}{|l|c|}
\hline Average torque & Value [N.m] \\
\hline MT Air-gap (FEA) & -19.5 \\
\hline MT Air-gap (SDM) & -23.5 \\
\hline VWP (FEA) & -18.7 \\
\hline MT Interface (SDM) & -23.0 \\
\hline
\end{tabular}

With the new conditions, Fig. 19 and Fig. 20 respectively show the radial and tangential Lumped Forces, but without the previous MT Radial and MT Tooth Tip which are not adequate for a vibroacoustic study. It is observable that the saturation effect is not introducing new temporal harmonics but the effect on the amplitude of the integrated quantities become obvious. The saturation is reducing the amplitude of the magnetic field in the air-gap, but the relative amplitude stay equivalent to the linear case. Since the SDM simulation is not accounting for the saturation, the torque (or tangential force) amplitude of the SDM based methods are higher than FEA based MT methods. The methods which are giving close results both in linear and saturated conditions are the MT Air-gap (SDM), the MT Air-gap (FEA) and the VWP. Even though MT and the VWP were previously not providing the same magnetic pressure distribution, the principle of global forces conservation is visible here. It is also important to notice the conservation of the time harmonics when the saturation effect is introduced. Then they are compared in terms of amplitude differences according to Eq. (15) in the logarithmic scale in Table X and Table XI. Since the static load does not contribute to the noise of electrical machines, only the maximum difference on the harmonics is observed.

In the end, the observable errors produced by the MT Airgap stay small in both linear and saturated cases compared

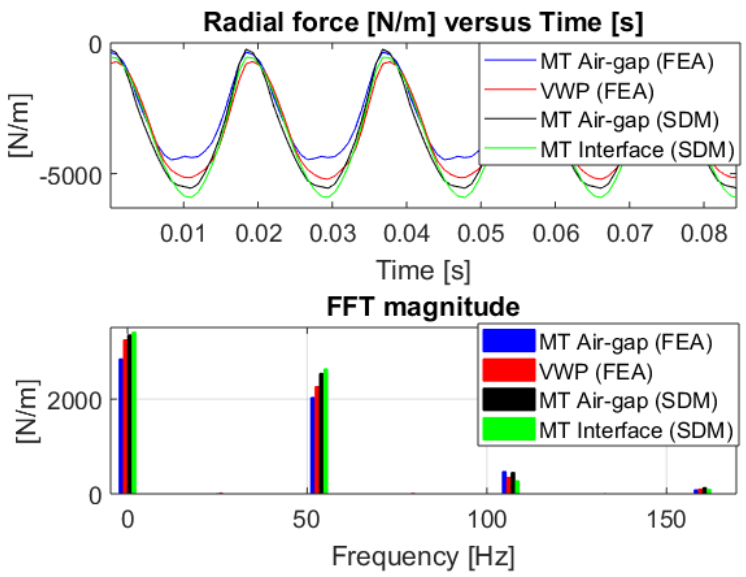

Fig. 19. Radial lumped force during one revolution and its FFT according to different methods with a non linear B-H curve

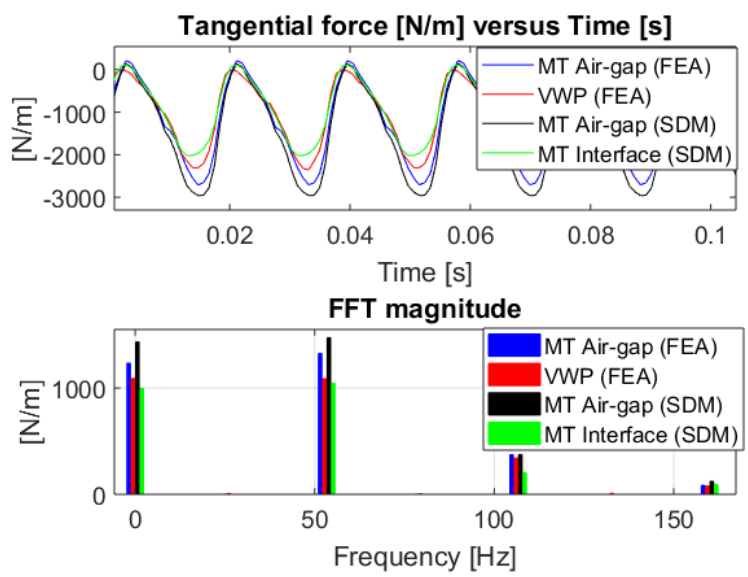

Fig. 20. Tangential lumped force during one revolution and its FFT according to different methods with a non linear B-H curve

TABLE $\mathrm{X}$

ACOUSTIC AMPLITUDE RELATIVE DEVIATION FOR EACH HARMONIC WITH RESPECT TO RADIAL LUMPED FORCE

\begin{tabular}{|l|c|c|c|}
\cline { 2 - 4 } \multicolumn{1}{c|}{} & \multicolumn{3}{c|}{ Considered harmonic } \\
\cline { 2 - 4 } \multicolumn{1}{c|}{} & $\mathrm{f} 1$ & $\mathrm{f} 2$ & $\mathrm{f}$ \\
\hline Lumped Force Method & Acoustic amplitude error [dB] \\
\hline MT Air-gap (FEA) & -2.2 & +5.1 & -1.5 \\
\hline MT Air-gap (SDM) & +1.5 & +3.3 & +7.6 \\
\hline MT Interface (SDM) & +2.5 & -6.0 & +1.7 \\
\hline \hline \multirow{4}{*}{} & \multicolumn{3}{|c|}{ Reference amplitude (VWP) } \\
\cline { 2 - 4 } & $155 \mathrm{~dB}$ & $119 \mathrm{~dB}$ & $91 \mathrm{~dB}$ \\
\hline
\end{tabular}

TABLE XI

ACOUSTIC AMPLITUDE RELATIVE DEVIATION FOR EACH HARMONIC WITH RESPECT TO TANGENTIAL LUMPED FORCE

\begin{tabular}{|l|c|c|c|}
\cline { 2 - 4 } \multicolumn{1}{c|}{} & \multicolumn{3}{c|}{ Considered harmonic } \\
\cline { 2 - 4 } \multicolumn{1}{c|}{} & $\mathrm{f} 1$ & $\mathrm{f} 2$ & $\mathrm{f} 3$ \\
\hline Lumped Force Method & Acoustic amplitude error [dB] \\
\hline MT Air-gap (FEA) & +3.2 & +2.0 & -0.2 \\
\hline MT Air-gap (SDM) & +5.1 & +1.7 & +4.9 \\
\hline MT Interface (SDM) & -1.3 & -9.10 & -0.3 \\
\hline \multirow{4}{*}{ Reference amplitude (VWP) } \\
\cline { 2 - 4 } & $140 \mathrm{~dB}$ & $117 \mathrm{~dB}$ & $91 \mathrm{~dB}$ \\
\hline
\end{tabular}

to the reference acoustic amplitude computed from Eq. (15) 
with the VWP. Such that any of these lumped force mapping procedures can be apply for the physical interpretation of the noise in electrical machine. Indeed the knowledge of which harmonic excites the structural mode is often enough for the design or the diagnostic of an electrical machine vibroacoustic response.

\section{CONCLUSION}

This paper proposes a comparison between different magnetic forces computation methods for vibro-acoustic purpose. The local magnetic pressure differs between methods (in section IV-A and the MT methods computed in the air-gap do not properly compute the local magnetic pressure especially in the slots and close to geometrical singularities. The idea to compare force methods under integrated form rely on the hypothesis that stator's teeth are more likely to convey global efforts. An adapted geometry for this hypothesis is long and thin teeth which are concentrating considerable radial and tangential efforts on teeth's tips. For this topology, the paper shows that Lumped Force mapping applied at the center of the tooth tip for vibro-acoustic does not really depend on the method used to compute magnetic forces if the method is correctly conserving global quantities (especially torque). This can be achieved by integrating the Maxwell Tensor between two slot opening. Moreover the last part of the paper shows that the assumptions of the Lumped Force method are weakened by the saturation. However, the observed differences are not a real problem for two reasons: firstly the harmonics are correctly predicted such that the resonance with structural modes can also be predicted by any of the method used in the saturation section. Secondly, the amplitude differences stay quite low when considering the equivalent acoustic amplitude values. Thus, with the advised three methods (MT Air-Gap SDM/FEA and VWP) the vibroacoustic design and optimization with Lumped Force of electrical machine with similar type of topology is equivalent. Nevertheless, the VWP is strongly recommended for further studies such as tooth tip geometry influence or saturation influence. Knowing that some geometries are more sensitive to saturation, there is certainly a link between the geometry and the validity of the lumped force methods. The characterization of this sensitivity is the matter of further work.

Therefore the advantages of using the Maxwell Tensor in the air gap with Lumped Force mapping (as it is done in MANATEE software) are: the compatibility with any electromagnetic fields computations (SDM, FEM, PMMF ...), it does not require a precise knowledge on the stator geometry (at least for standard geometries), it is very light in term of computational cost and can be as accurate as nodal methods.

The authors goal is to provide in a later paper further investigations on a comparison in the electrical machine noise context between nodal forces projection (which should be more accurate) and simplified methods such as lumped force mapping.

\section{ACKNOWLEDGMENT}

The authors would like to thank Olivier Barré for sharing his knowledge on magneto-mechanical physics.

\section{REFERENCES}

[1] E. Devillers, J. Le Besnerais, T. Lubin, M. Hecquet, and J.-P. Lecointe, "A review of subdomain modeling techniques in electrical machines: performances and applications," in Electrical Machines (ICEM), 2016 XXII International Conference on. IEEE, 2016, pp. 86-92. [Online]. Available: http://ieeexplore.ieee.org/document/7732510/

[2] K. Lu, P. P. O. Rasmussen, and E. Ritchie, "An Analytical Equation for Cogging Torque Calculation in Permanent Magnet Motors," 17 th International Conference on ..., 2006. [Online]. Available: http://vbn.aau.dk/ws/files/7178120/PMM1\{_\}7\{_\}full.pdf

[3] O. Barré, “Contribution à l'étude des formulations de calcul de la force magnétique en magnétostatique, approche numérique et validation expérimentale," Ph.D. dissertation, Centrale Lille, 2003. [Online]. Available: https://tel.archives-ouvertes.fr/tel-00005921/document

[4] J. Kirtley, James L., Class Notes 1: Electromagnetic Forces, 2005. [Online]. Available: http://web.mit.edu/course/6/6.685/www/chapter1. pdf

[5] K. J. Meessen, J. J. H. Paulides, and E. A. Lomonova, "Force calculations in 3-D cylindrical structures using fourier analysis and the maxwell stress tensor," IEEE Transactions on Magnetics, vol. 49, no. 1, pp. 536-545, 2013. [Online]. Available: http: //ieeexplore.ieee.org/document/6228537/

[6] J. L. Coulomb and G. Meunier, "Finite element implementation of virtual work principle for magnetic or electric force and torque computation," IEEE Transactions on Magnetics, vol. 20, no. 5, pp. 1894-1896, 1984. [Online]. Available: http://ieeexplore.ieee.org/document/1063232/

[7] G. Kumar, "Noise prediction for electric motors by coupling electromagnetic and vibroacoustic simulation tools," in Proceedings of NAFEMS conference, 2014. [Online]. Available: https://www.nafems. org/.../uk_2014_mpconf/abstracts/041_kumar.pdf

[8] F. Chauvicourt, C. Faria, A. Dziechciarz, and C. Martis, "Infuence of rotor geometry on nvh behavior of synchronous reluctance machine," in Ecological Vehicles and Renewable Energies (EVER), 2015 Tenth International Conference on. IEEE, 2015, pp. 1-6. [Online]. Available: http://ieeexplore.ieee.org/document/7112973/

[9] T. Hattori, "Starting with vibration noise analyses," p. Vol. 1, 2014. [Online]. Available: https://www.jmag-international.com/ newsletter/201401/05.html

[10] H. Ennassiri and F. Zidat, "Magneto-vibro-acoustic analysis linking flux $($ to ansys $($ mechanical," pp. CEDRAT News - N 6, 2016. [Online]. Available: http://www.cedrat.com/Publications/

[11] J. Hallal, "Etudes des vibrations d'origine électromagnétique d'une machine électrique: conception optimisée et variabilité du comportement vibratoire," Ph.D. dissertation, Compiègne, 2014. [Online]. Available: www.theses.fr/2014COMP1900/abes

[12] P. Lombard, "Summary -vibro-acoustic coupling," 2017.

[13] V. Wilow, "Electromagnetical model of an induction motor in comsol multiphysics," 2014. [Online]. Available: http://www.diva-portal.se/ smash/get/diva2:790873/FULLTEXT01.pdf

[14] M. K. Nguyen, "Master's thesis : Predicting electromagnetic noise in induction motors," 2014. [Online]. Available: http://www.diva-portal.se/ smash/get/diva2:742541/FULLTEXT01.pdf

[15] M. Nguyen, R. Haettel, and A. Daneryd, "Prediction of noise generated by electromagnetic forces in induction motors," 2014. [Online]. Available: https://www.comsol.nl/paper/download/199305/haettel_paper. pdf

[16] M. Solveson, C. Rathod, M. Hebbes, G. Verma, and T. Sambharam, "Electromagnetic Force Coupling in Electric Machines," ANSYS Inc, Tech. Rep., 2011. [Online]. Available: http://resource.ansys.com

[17] X. Ge, "Simulation of vibrations in electrical machines for hybridelectric vehicles," Ph.D. dissertation, MS Thesis, Department of Applied Mechanics, Chalmers University of Technology, Göteborg (Sweden), 2014. [Online]. Available: http://publications.lib.chalmers.se/ records/fulltext/199927/199927.pdf

[18] F. Lin, S. Zuo, W. Deng, and S. Wu, "Modeling and analysis of electromagnetic force, vibration, and noise in permanent-magnet synchronous motor considering current harmonics," IEEE Transactions on Industrial Electronics, vol. 63, no. 12, pp. 7455-7466, 2016. [Online]. Available: http://ieeexplore.ieee.org/document/7518596/

[19] "Guide for me2d user - cobham technical services."

[20] K. Reichert, "A simplified approach to permanent magnet and reluctance motor characteristics determination by finite-element methods," COMPEL-The international journal for computation and mathematics in electrical and electronic engineering, vol. 25, no. 2, pp. 368-378, 2006. 
[21] N. Wirth, "Simulation of flow and electro-magnetic induced vibrations - mapping procedures for nvh analyses," 2016.

[22] M. Rossi and J. Le Besnerais, "Vibration reduction of inductors under magnetostrictive and maxwell forces excitation," IEEE Transactions on Magnetics, vol. 51, no. 12, pp. 1-6, 2015. [Online]. Available: http://ieeexplore.ieee.org/document/7208876/

[23] P. Dular and C. Geuzaine, "Getdp reference manual: the documentation for getdp, a general environment for the treatment of discrete problems," University of Liège, 2013. [Online]. Available: http://getdp.info/

[24] J. Le Besnerais, "Fast prediction of variable-speed acoustic noise and vibrations due to magnetic forces in electrical machines," in ICEM International Conference on Electrical Machines, 2016. [Online]. Available: http://ieeexplore.ieee.org/document/7732836/

[25] A. Bossavit, "A note on the uniqueness of the poynting vector and of the maxwell tensor," International Journal of Numerical Modelling: Electronic Networks, Devices and Fields, 2016. [Online]. Available: http://onlinelibrary.wiley.com/doi/10.1002/jnm.2214/full

[26] A. Bermúdez, A. Rodríguez, and I. Villar, "Extended formulas to compute resultant and contact electromagnetic force and torque from maxwell stress tensors," IEEE Transactions on Magnetics, vol. 53, no. 4, pp. 1-9, 2017. [Online]. Available: http://ieeexplore.ieee.org/ document/7762235/

[27] F. Henrotte and K. Hameyer, "A theory for electromagnetic force formulas in continuous media," IEEE Transactions on Magnetics, vol. 43, no. 4, pp. 1445-1448, 2007. [Online]. Available: http: //ieeexplore.ieee.org/document/4137733/

[28] Z. Zhu, L. Wu, and Z. Xia, "An accurate subdomain model for magnetic field computation in slotted surface-mounted permanent-magnet machines," IEEE Transactions on Magnetics, vol. 46, no. 4, pp. 1100$1115,2010$.

[29] A. Saito, M. Kuroishi, and H. Nakai, "Vibration prediction method of electric machines by using experimental transfer function and magnetostatic finite element analysis," Journal of Physics: Conference Series, vol. 744, no. 1, p. 012088, 2016. [Online]. Available: http://stacks.iop.org/1742-6596/744/i=1/a=012088

[30] D. Meeker, "Finite element method magnetics," FEMM, vol. 4, p. 32 , 2010.

[31] J. Coulomb, G. Meunier, and J. Sabonnadiere, "An original stationary method using local jacobian derivative for direct finite element computation of electromagnetic force, torque and stiffness," Journal of Magnetism and magnetic Materials, vol. 26, no. 1-3, pp. 337-339, 1982.

[32] R. E. Rosensweig, Ferrohydrodynamics. Courier Corporation, 2013.

[33] A. Bossavit, "Bulk forces and interface forces in assemblies of magnetized pieces of matter," IEEE Transactions on Magnetics, vol. 52, no. 3, pp. 1-4, 2016. [Online]. Available: http://ieeexplore.ieee.org/ abstract/document/7286815/

[34] L. De Medeiros, G. Reyne, and G. Meunier, "Comparison of global force calculations on permanent magnets," IEEE Transactions on magnetics, vol. 34, no. 5, pp. 3560-3563, 1998. [Online]. Available: http://ieeexplore.iee.org/document/717840/

[35] W. N. Fu, P. Zhou, D. Lin, S. Stanton, and Z. J. Cendes, "Magnetic force computation in permanent magnets using a local energy coordinate derivative method," IEEE Transactions on Magnetics, vol. 40, no. 2 II, pp. $683-686,2004$.

[36] F. Henrotte and K. Hameyer, "Computation of electromagnetic force densities: Maxwell stress tensor vs. virtual work principle," Journal of Computational and Applied Mathematics, vol. 168, no. 1-2, pp. 235243, 2004.

[37] J. Roivainen et al., "Unit-wave response-based modeling of electromechanical noise and vibration of electrical machines," 2009. [Online]. Available: http://lib.tkk.fi/Diss/2009/isbn9789512299119/

[38] E. Devillers, M. Hecquet, J. Le Besnerais, and M. Régniez, "Tangential effects on magnetic vibrations and acoustic noise of induction machines using subdomain method and electromagnetic vibration synthesis," in Electric Machines and Drives Conference (IEMDC), 2017 IEEE International. IEEE, 2017, pp. 1-8. [Online]. Available: http://ieeexplore.ieee.org/document/8002072/

[39] J. Hallal, F. Druesne, and V. Lanfranchi, "Study of electromagnetic forces computation methods for machine vibration estimation," ISEF2013, Ohrid, Macedonia, 2013.

[40] M. Krishnamurthy and B. Fahimi, "Qualitative analysis of force distribution in a 3-phase permanent magnet synchronous machine," in Electric Machines and Drives Conference, 2009. IEMDC'09. IEEE International. IEEE, 2009, pp. 1105-1112. [Online]. Available: http://ieeexplore.ieee.org/document/5075342/

[41] J. Coulomb, "A methodology for the determination of global electromechanical quantities from a finite element analysis and its application to the evaluation of magnetic forces, torques and stiffness," IEEE Transactions on Magnetics, vol. 19, no. 6, pp. 2514-2519, Nov 1983. [Online]. Available: http://ieeexplore.ieee.org/document/1062812/ [42] M. Boesing, T. Schoenen, and K. A. Kasper, "Vibration Synthesis for Electrical Machines Based on Force Response Superposition," IEEE Transactions on Magnetics, vol. 46, no. 8, pp. 2986-2989, aug 2010. [Online]. Available: http://ieeexplore.ieee.org/document/5513016/

[43] Z. Ren, "Comparison of Different Force Calculation Methods in 3D Finite Element Modelling," IEEE Transactions on Magnetics, vol. 30, no. 5, pp. 3471-3474, 1994.

[44] S. Sathyan, A. Belahcen, J. Kataja, F. Henrotte, A. Benabou, and Y. Le Menach, "Computation of Magnetic Forces Using Degenerated Air-Gap Element," IEEE Transactions on Magnetics, vol. 53, no. 6, pp. 1-4, jun 2017. [Online]. Available: http://ieeexplore.ieee.org/document/7828131/

[45] A. Youmssi, "A three-dimensional semi-analytical study of the magnetic field excitation in a radial surface permanent-magnet synchronous motor," IEEE transactions on magnetics, vol. 42, no. 12, 2006.

[46] H. Hu, J. Zhao, X. Liu, Y. Guo, and J. Zhu, "No-load magnetic field and cogging force calculation in linear permanent-magnet synchronous machines with semiclosed slots," IEEE Transactions on Industrial Electronics, vol. 64, no. 7, pp. 5564-5575, 2017. [Online]. Available: http://ieeexplore.ieee.org/document/7801011/

[47] D. Howe and Z. Q. Zhu, "The influence of finite element discretisation on the prediction of cogging torque in permanent magnet excited motors," IEEE Transactions on Magnetics, vol. 28, no. 2, pp. 10801083, 1992.

[48] A. Wignall, A. Gilbert, and S. Yang, "Calculation of forces on magnetised ferrous cores using the maxwell stress method," IEEE Transactions on Magnetics, vol. 24, no. 1, pp. 459-462, 1988. [Online]. Available: http://ieeexplore.ieee.org/document/43956/

[49] J. Mizia, K. Adamiak, A. Eastham, and G. Dawson, "Finite element force calculation: comparison of methods for electric machines," IEEE Transactions on Magnetics, vol. 24, no. 1, pp. 447-450, 1988. [Online]. Available: http://ieeexplore.ieee.org/document/43953/

[50] W. N. Fu and S. L. Ho, "Error Estimation for the Computation of Force Using the Virtual Work Method on Finite Element Models," IEEE Transactions on Magnetics, vol. 45, no. 3, pp. 1388-1391, 2009.

[51] P. Kotter, W. Bischof, R. Kennel, O. Zirn, K. Wegener, G. Systems, and R. B. Gmbh, "Noise-Vibration-Harshness-Modeling and Analysis of Induction Drives in E-Mobility Applications," 2017.

[52] C. R. Sullivan and S. R. Sanders, "Models for induction machines with magnetic saturation of the main flux path," in Industry Applications Society Annual Meeting, 1992., Conference Record of the 1992 IEEE. IEEE, 1992, pp. 123-131.

[53] Z. Azar, Z. Zhu, and G. Ombach, "Influence of electric loading and magnetic saturation on cogging torque, back-emf and torque ripple of pm machines," IEEE Transactions on Magnetics, vol. 48, no. 10, pp. $2650-2658,2012$. 